\title{
Chromophobe adenoma of the pituitary with Cushing's syndrome and skin pigmentation
}

\author{
NuAla Sterling \\ M.B., M.R.C.P.
}

\author{
M. R. P. HALL \\ M.A., B.M., F.R.C.P.
}

\begin{abstract}
Department of Geriatric Medicine, Southampton General Hospital, and Faculty of Medicine, University of Southampton, Southampton SO9 4XY
\end{abstract}

\begin{abstract}
Summary
A 76-year-old man with pigmentation and Cushing's disease is described, who was found to have a large chromophobe adenoma of the pituitary. Despite normal skull X-rays the presence of bitemporal hemianopia led to the diagnosis which was later confirmed at post-mortem. Adrenalectomy performed in the treatment of Cushing's disease may be followed by skin pigmentation and an enlarging pituitary tumour (Nelson's syndrome), changes which are commonly attributed to the removal of the negative feed-back mechanism. The spontaneous occurrence of these changes in this patient who did not undergo adrenalectomy supports the view that a pituitary tumour pre-exists in cases of Nelson's syndrome and emphasizes the importance of directing initial treatment to the pituitary.
\end{abstract}

\section{Introduction}

Cushing's disease is rare in the elderly and may escape suspicion because many of the characteristic symptoms are common in old age. Therapeutic adrenalectomy may be followed by increasing skin pigmentation and the development of a pituitary tumour (Nelson's syndrome). The case is now described of an elderly man in whom these features arose spontaneously.

\section{Case report}

A 76-year-old man with congestive cardiac failure, diabetes mellitus and immobility was referred to the geriatric unit for rehabilitation. Eighteen months $\vec{\overrightarrow{ }}$ earlier skin pigmentation and glycosuria had been $\stackrel{\sigma}{\omega}$ noted following ophthalmological examination for $\overrightarrow{0}$ failing vision. There was a 5-year history of treated 3 hypertension (initial BP 220/125 mmHg). Examina- ir tion revealed a depressed and irritable man who had truncal obesity, a buffalo hump, marked pigmentation $\frac{\hbar}{\sigma}$ on exposed areas and superficial abrasions over the of sacrum and feet. He had generalized muscle weak- $\stackrel{\odot}{\perp}$ ness but normal tendon and plantar responses. There was a left third cranial nerve palsy an optic atrophy. Visual fields showed a bitempora is hemianopia with additional loss of the left lowef nasal quadrant.

The $\mathrm{Hb}$ and $\mathrm{WBC}$ count were normal. Plasma urea $6.3 \mathrm{mmol} / 1(38 \mathrm{mg} / \mathrm{dl})$; sodium $141 \mathrm{mmolg}$ 는 $(\mathrm{mEq} / \mathrm{l})$; potassium $2.7 \mathrm{mmol} / \mathrm{l}(\mathrm{mEq} / \mathrm{l})$; chloride $\overrightarrow{0}$ $91 \mathrm{mmol} / \mathrm{l}(\mathrm{mEq} / \mathrm{l})$; bicarbonate $38 \mathrm{mmol} / \mathrm{l}(\mathrm{mEq} / \mathbb{\&}$ Fasting blood sugar was $5.4 \mathrm{mmol} / 1(98 \mathrm{mg} / \mathrm{dl})$ an a 2-hr post-prandial level $19.46 \mathrm{mmol} / 1(350 \mathrm{mg} / \mathrm{dl})$ with $2 \%$ glycosuria.

Radiological examination showed generalized osteoporosis and vertebral wedging. There was some cardiac enlargement but the lung fields were clear. The pituitary fossa was normal except for an ill defined dorsum sellae. Intravenous pyelography and nephrotomography showed no evidence of adrenal tumour. Plasma cortisol was high [1380 nmol/l $(50.5 \mu \mathrm{g} / \mathrm{dl})$ fasting; $1132 \mathrm{nmol} / \mathrm{l}(41 \mu \mathrm{g} / \mathrm{dl})$ at 21.00 hours] and diurnal rhythm was lost. Suppression could not be obtained during a high dose dexamethasone test (Table 1) but Cushing's disease

TABLE 1. Steroid estimations during dexamethasone suppression test

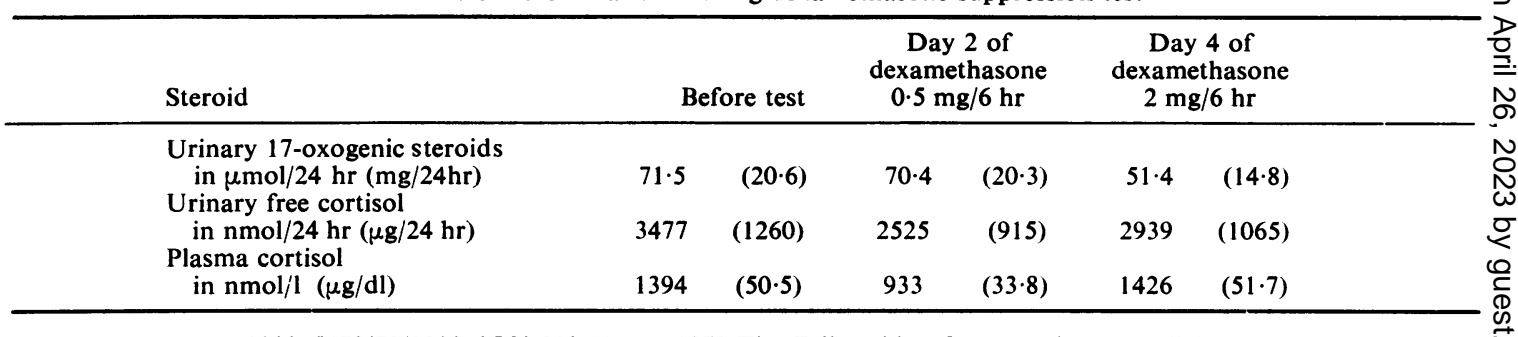




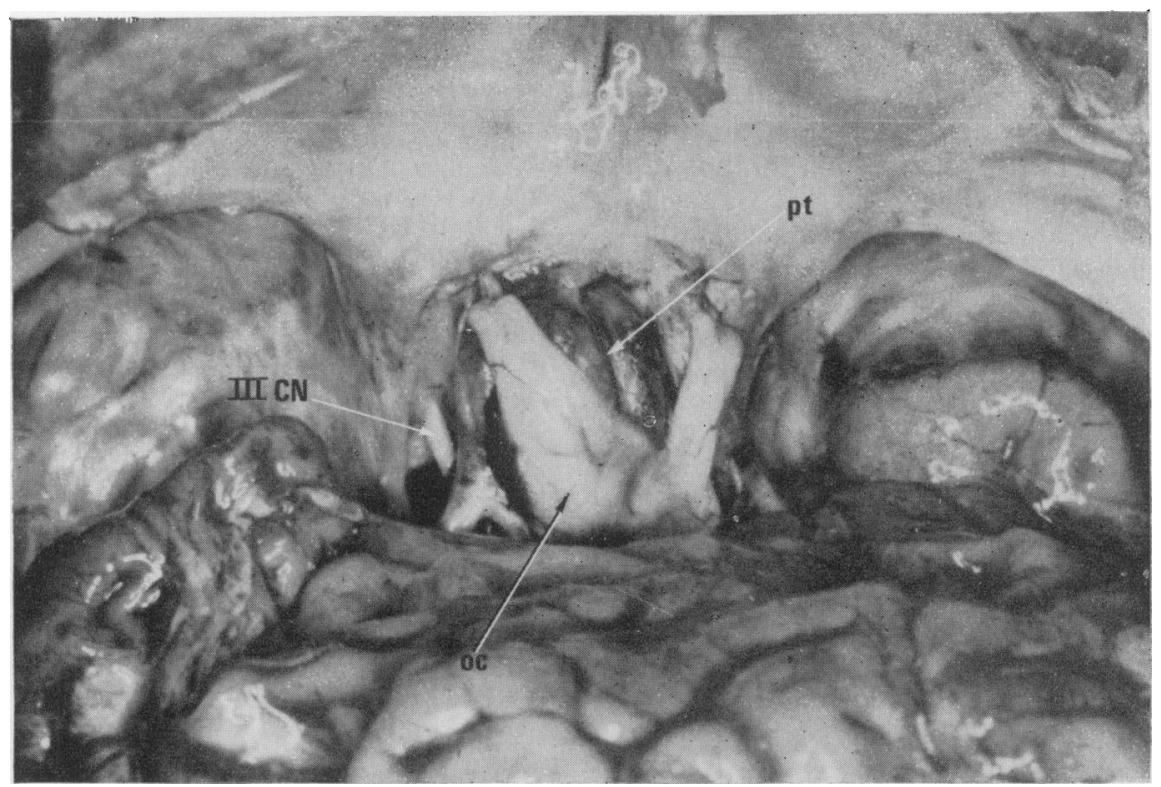

FIG. 1. Optic chiasma (oc) and pituitary tumour (pt) seen from above showing stretched optic nerves and relation to third cranial nerve (III CN).

due to a pituitary tumour was diagnosed on the basis of the eye signs. Before irradiation he suddenly died.

Post-mortem revealed a large red-brown tumour (Fig. 1) $3 \mathrm{~cm}$ in diameter protruding from the pituitary fossa, stretching the optic chiasma and elevating both optic nerves particularly the left. Histology showed a chromophobe adenoma. The symmetrically hyperplastic adrenal glands weighed $12 \mathrm{~g}$ (left) and $11 \mathrm{~g}$ (right). There was no evidence of lung tumour.

\section{Discussion}

Pituitary-dependent Cushing's disease is rare, is more common in women than men, and the majority of cases occur in the third to fifth decade (Besser and Edwards, 1972). Many of the presenting features are common symptoms in old age which may account for the scarcity of reports of the disease in the elderly. It remained unsuspected in this patient for a long time fortuitously allowing documentation of the untreated disease. Review of the medical records and old photographs suggested that the condition had been present for at least 6 years and that in the last 2 years skin pigmentation was associated with signs of a pituitary tumour which was rapidly progressive in the final stages.

Although pigmentation may occur as an early symptom the time relationship to treatment is not given in the review of the natural history of the disease by Plotz, Knowlton and Ragan in 1952. Where pigmentation was the presenting symptom in 2 of the cases reviewed by Marks (1959) it was associated with pituitary carcinoma. The radiologically intact pituitary fossa and lack of steroid suppression to dexamethasone might have suggested the presence of an adrenal tumour in this patient but Cope (1966) advised caution in the interpretation of suppression tests. The detection of the eye signs was sufficient for the clinical diagnosis to be made and highlights the importance of early visual field examination (Lyle and Clover, 1961).

Cushing's disease is a direct consequence of adrenocortical hyperactivity but the relationship of pituitary tumours to adrenal hyperplasia is uncertain. The significance of the small basophil adenoma originally described by Cushing (1932) is doubtful since Costello (1936) observed this as a common isolated post-mortem finding.

Nelson et al. (1958) reported the development of chromophobe adenoma, pigmentation and high non-suppressable levels of ACTH following bilateral adrenalectomy for Cushing's disease and concluded that the tumour might result from the removal of the negative feed-back effect of the high cortisol levels. This explanation has remained subject to debate, for Salassa et al. (1959) described similar patients with Cushing's disease and chromophobe adenomata in whom melanosis was evident, but 9 of 
the 12 cases had evidence of the tumour before operation.

The marked pigmentation and adrenal hyperplasia in this patient with chromophobe adenoma are evidence for increased secretion of anterior pituitary hormones which supports Salassa's view that the primary abnormality in some cases of Cushing's disease is an adrenocorticotrophichormone (ACTH) secreting tumour of the pituitary. This stimulates adrenal hyperplasia, perhaps with partial control of the tumour until adrenalectomy is performed. In the present patient, however, despite high cortisol levels, the tumour continued to expand, which suggests that adrenalectomy preceding Nelson's syndrome may merely stimulate the growth of a pre-existing tumour. This emphasises the logic of directing treatment to the pituitary, an approach which has been increasingly successful (Leading Article, 1977).

\section{Acknowledgments}

We are indebted to Dr P. J. Gallagher for the pathological studies and $\mathrm{Mr}$ F. C. Grimes for the steroid estimations.

\section{References}

Besser, G.M. \& Edwards, C.R.W. (1972) Cushing's syndrome. Clinics in Endocrinology and Metabolism, 1, 451.

Cope, C.L. (1966) The adrenal cortex in internal medicine. British Medical Journal, $2,847$.

Costello, R.T. (1936) Subclinical adenoma of the pituitary gland. American Journal of Pathology, 12, 205.

Cushing, H. (1932) The basophil adenomas of the pituitary body and their clinical manifestations (pituitary basophilism). Bulletin of the Johns Hopkins Hospital, 50, 137.

LEADING ARTICLE (1977) Pituitary-dependent Cushing's disease. British Medical Journal, 1, 1049.

Lyle, T.K. \& Clover, P. (1961) Ocular symptoms and signs in pituitary tumours. Proceedings of the Royal Society of Medicine, 54, 611.

MARKs, V. (1959) Cushing's syndrome occurring with pituitary chromophobe tumours. Acta endocrinologica. Copenhagen, 32, 527.

Nelson, D.H., Meakin, J.W., Dealy, J.B., Matson, D.D., EMmerson, K. \& THORN, G.W. (1958) ACTH-producing tumor of the pituitary gland. New England Journal of Medicine, 259, 161.

Plotz, C.M., Knowlton, A.I. \& Ragan, C. (1952) The natural history of Cushing's syndrome. American Journal of Medicine, 13, 597.

Salassa, R.M., Kearns, T.P., Kernohan, J.W., Sprague, R.G. \& MACCARTY, C.J. (1959) Pituitary tumors in patients with Cushing's syndrome, Journal of Clinical Endocrinology and Metabolism, 19, 1523. 